\title{
Confirmation of tracheal intubation time in adult patients
}

\author{
Bailong $\mathrm{Hu}^{1} \Subset \cdot$ Haiyan $\mathrm{Zhou}^{2} \cdot$ Yansong $\mathrm{Li}^{3}$
}

Received: 4 October 2015 / Accepted: 5 November 2015 / Published online: 25 November 2015

(C) Japanese Society of Anesthesiologists 2015

\section{To the Editor:}

We have read the article written by Arlsan et al. with great interest [1]. It is a welcome investigation which compared the use of Airtraq ${ }^{\mathrm{TM}}$, Glidescope ${ }^{\mathrm{TM}}$, and Fastrach ${ }^{\mathrm{TM}}$ devices in face-to-face intubation with adult patients. We thank the authors for this article because it addresses an important issue in face-to-face intubation. However, we have a question regarding the accuracy of the tracheal intubation time recorded in these adult patients.

In the study, intubation time was defined as the time from when the device entered the oral cavity until the tracheal tube was observed going through the vocal cords. However, if the authors could not see the vocal cord in some patient cases, how did the authors record the intubation time? In fact, in the Airtraq group, one patient was a Cormack-Lehane grade III, which means the vocal cords were not visible. The authors could not accurately record the intubation time of this patient according to their own definition, which may have caused intubation time bias in the Airtraq group. Fun et al. [2] have defined intubation time as the time from when the laryngoscope passed the patient's lips to the time when the correct placement of the tracheal tube was confirmed by capnography. As is well known, capnography remains the gold standard for confirming correct endotracheal tube placement. We suggest that Arslan et al. should have defined intubation time from when the device entered the patient's mouth until end-tidal carbon dioxide was detected.

\section{Compliance with ethical standards}

Conflict of interest None declared.

\section{References}

1. Arslan ZI, Alparslan V, Ozdal P, Toker K, Solak M. Face-toface tracheal intubation in adult patients: a comparison of the Airtraq $^{\mathrm{TM}}$, Glidescope $\mathrm{TM}^{\mathrm{TM}}$ and Fastrach ${ }^{\mathrm{TM}}$ devices. J Anesth. 2015;29:1-6.

2. Fun W, Lim Y, Teoh W. Comparison of the GlideScope ${ }^{\circledR}$ video laryngoscope vs. the intubating laryngeal mask for females with normal airways. Eur J Anesthesiol. 2007;24:486-91.

B. L. Hu and H. Y. Zhou contributed equally to the letter.

Bailong $\mathrm{Hu}$

375896605@qq.com

1 Department of Anesthesiology, The Affiliated Hospital of Guizhou Medical University, Guiyang 550004, China

2 Department of Clinical Research Centre, The Affiliated Hospital of Guizhou Medical University, Guiyang 550004, China

3 Department of Anesthesiology, West China Hospital, Sichuan University, Chengdu 610041, China 